\title{
Using Grain Refiner Al-3Ti-0.3C to Improve Al-Water Reaction Rate and Yield
}

\author{
DongDong Zhou and Jun Fan* \\ College of Mechanical Engineering, Xinjiang University, Urumqi, China
}

Al-Ga-In-Sn alloys with different amounts of a refining agent (Al-3Ti-0.3C) were prepared via atmospheric pressure casting. The microstructures of the resulting alloys were analyzed via X-ray diffraction, scanning electron microscopy, and energy-dispersive X-ray spectroscopy. With an increase in the Ti content (through Al-3Ti-0.3C) from 0.03 mass $\%$ to 0.24 mass $\%$, the grain size of the alloy was refined from 181 to $73 \mu \mathrm{m}$. In addition, $\mathrm{Al}$ dendrites of several micrometers are observed in the grain of $\mathrm{Al}$ alloy.

Our experimental results for the Al-water reaction at different temperatures of water indicate that the hydrogen production rate of the alloy with a Ti content of 0.12 mass $\%$ is the highest; in particular, it is about twice that of the alloy without Ti. On further increasing the Ti content, the hydrogen production rate of the alloy-water reaction remained almost unchanged. The hydrogen yield of the alloy decreases from $88 \%$ to $66 \%$ with an increase in the Ti content from 0.03 mass $\%$ to 0.24 mass $\%$ at $30^{\circ} \mathrm{C}$. However, when the water temperature is increased to $70{ }^{\circ} \mathrm{C}$, the hydrogen yield of the alloy increases to more than $90 \%$.

Based on our observations, the mechanism of grain refinement and its effect on the reaction between the alloy and water was proposed. [doi:10.2320/matertrans.MT-MK2019005]

(Received November 5, 2019; Accepted February 10, 2020; Published April 24, 2020)

Keywords: Al alloy, microstructures, hydrogen rate, hydrogen yield, Al-water reaction

\section{Introduction}

Hydrogen is an efficient and clean source of energy; which is one of the primary fuels used in new hybrid vehicles. The preparation methods for hydrogen mainly include electrolytic water method, microbial decomposition method, and hydrocarbon pyrolysis method. ${ }^{1-21)}$ However, in recent years, preparation of hydrogen through Al-water reaction has attracted significant interest from researchers. Al is lightweight, has high specific energy, and is abundant in nature. Furthermore, $\mathrm{Al}(\mathrm{OH})_{3}$, which is a byproduct of the $\mathrm{Al}$-water reaction, is nonpolluting and can be recycled. ${ }^{22,23)}$

Under normal conditions, Al does not react with water; however, when the temperature of water is higher than $298 \mathrm{~K}$, the Gibbs free energy $\mathrm{G}$ of the reaction between $\mathrm{Al}$ and water is less than 0 ; therefore, according to thermodynamics, at such high temperatures, $\mathrm{Al}$ and water can react spontaneously and release heat. Nevertheless, the reaction of Al with water is difficult to achieve because of the dense oxide film that forms on the surface of $\mathrm{Al}$, which hinders further contact between $\mathrm{Al}$ and water. $^{24)}$ Therefore, removal of the dense oxide film that forms on the Al surface is key to achieve continuous reaction between $\mathrm{Al}$ and water. Considerable research has been conducted on eliminating the oxide film on the surface of $\mathrm{Al}$ to promote the reaction between $\mathrm{Al}$ and water. $^{25-31)}$ The primary methods to achieve this include addition of different corrosive media in the aqueous solution, mixing metal and oxide in Al by mechanical alloying, and alloying Al with low-melting metals ( $\mathrm{Ga}, \mathrm{In}, \mathrm{Sn}, \mathrm{Pb}, \mathrm{Bi}$ ), among others.

In particular, alloying low-melting metals (viz. Ga, In, and $\mathrm{Sn}$ ) with $\mathrm{Al}$ is an effective method to enable a reaction between $\mathrm{Al}$ and water, ${ }^{32)}$ this is because these low-melting metals can form a liquid Ga-In-Sn (GIS) phase on the surface of the Al grains, which can not only destroy the dense oxide film on the Al surface, but also act as a channel for the

*Corresponding author, E-mail: 670203517@qq.com diffusion of $\mathrm{Al}$ atoms in $\mathrm{Al}$ grains to the interface where the $\mathrm{Al}$-water reaction is occurring, thus promoting a continuous reaction between the $\mathrm{Al}$ atoms and water.

Owing to its characteristics of low melting point, fast hydrogen production rate, high hydrogen conversion rate, and easy storage, Al-Ga-In-Sn alloy is suitable for production of hydrogen through its reaction with water. Through a systematic study of the Al-Ga-In-Sn alloy, it was found that its grain size, low-melting metal composition, and other alloy elements affect the Al-water reaction using the alloy. ${ }^{33-37)}$ Among these factors, the grain size of the $\mathrm{Al}$ alloy as well as the morphology and distribution of the GIS phase are the key factors affecting the hydrogen production rate and hydrogen conversion rate of the reaction. The results indicate that the smaller the grain size, the smaller the activation energy, and the faster the hydrogen production rate will be.

$\mathrm{Ti}$ is an effective element to refine the grain of the Al-GaIn-Sn alloy. He Tiantian et al. showed that when 0.5 mass $\%$ pure $\mathrm{Ti}$ is added to the Al-Ga-In-Sn alloy, the grain of the alloy changes from columnar to equiaxed. ${ }^{37)}$ In particular, when the Ti content is 1 mass\%, the grain size of $\mathrm{Al}$ can be refined to $60 \mu \mathrm{m}$. However, a high Ti content can inhibit the reaction rate between the alloy and water, reducing the hydrogen yield of the reaction. Furthermore, in practice, because $\mathrm{Ti}$ is an expensive metal, a high percentage of $\mathrm{Ti}$ in the alloy is also unfavorable in terms of the alloy preparation costs.

Considering this, as an alternative, Al-3Ti-0.3C is often used to refine the grain of the $\mathrm{Al}$ alloy. Compared with pure $\mathrm{Ti}, \mathrm{Al}-3 \mathrm{Ti}-0.3 \mathrm{C}$ is more conducive to the stability of heterogeneous nucleating particles in the $\mathrm{Al}$ melt; this is because $\mathrm{Al}-3 \mathrm{Ti}-0.3 \mathrm{C}$ can form stable $\mathrm{TiC}$ particles in the melt. Consequently, the $\mathrm{TiC}$ particles promote the formation of $\mathrm{TiAl}_{3}$ particles on the surface of Ti atoms in $\mathrm{Al}$ melt. ${ }^{38-40}$ ) In contrast, if pure $\mathrm{Ti}$ is added to the alloy, $\mathrm{TiAl}_{3}$ particles can only form when the Ti content exceeds 0.15 mass $\%$ through a peritectic reaction. Thus, a small amount of Al-3Ti-0.3C 
can effectively refine the $\mathrm{Al}$ grain of the alloy. Moreover, the low Ti content in the alloy on using the $\mathrm{Al}-3 \mathrm{Ti}-0.3 \mathrm{C}$ refiner can also prevent a degradation of the reaction efficiency between the alloy and water.

To the best of our knowledge, thus far, grain refinement using high amounts of the $\mathrm{Al}-3 \mathrm{Ti}-0.3 \mathrm{C}$ refiner in the $\mathrm{Al}-\mathrm{Ga}-$ In-Sn alloy, and the hindering effect of the reaction between $\mathrm{Al}-3 \mathrm{Ti}-0.3 \mathrm{C}$ and water on hydrogen production using the alloy remain unclear. Thus, in this work, the effect of Al-3Ti$0.3 \mathrm{C}$ addition on grain refinement of the Al-Ga-In-Sn alloy was studied. In particular, the relationship between the microstructure and interfacial phase composition of the alloy and reaction between $\mathrm{Al}$ and water was explored to find the amount of $\mathrm{Al}-3 \mathrm{Ti}-0.3 \mathrm{C}$ that can suitably refine the grain of the alloy. The microstructure of the refined alloy was studied using X-Ray diffraction (XRD) analysis, scanning electron microscopy (SEM), and energy-dispersive X-ray spectroscopy (EDX). Furthermore, the hydrogen production properties of the alloy and water at different temperatures were studied through the drainage gas collection method. Finally, the reaction mechanism between the refined alloy and water was proposed based on our results.

\section{Experiment Details}

Eight Al alloy ingots of $1 \mathrm{~kg}$ were formed using the traditional casting metallurgy method with different amounts of Al-3Ti-0.3C. The weights of the constituent low-melting metals $\mathrm{Ga}, \mathrm{In}$, and $\mathrm{Sn}$ were set to 3.8 mass $\%, 1.5$ mass\%, and 0.7 mass $\%$ that of $\mathrm{Al}$ for each ingot, respectively. The nominal compositions of the eight alloys are listed in Table 1. As starting materials, 99.99\%-pure $\mathrm{Al}, \mathrm{Ga}$, In, and $\mathrm{Sn}$ are used along with commercial Al-3Ti-0.3C wire. The ingots were melted in a graphite crucible at $750^{\circ} \mathrm{C}$ in a closed electric furnace. Then, a desired amount of the Al-3Ti-0.3C refiner was added to the melt in the crucible, which was maintained at $750^{\circ} \mathrm{C}$ for $10 \mathrm{~min}$. To ensure homogeneity, the melt was stirred with a clay-bonded steel ladle for about $30 \mathrm{~s}$, and then cast into a steel mold preheated to $150^{\circ} \mathrm{C}$.

The resulting alloy ingots were cut into 2-mm-thick square pieces with a $1-\mathrm{cm}$ side to perform microstructure analysis and Al-water reactivity measurements. The phase compositions of the alloys and reaction products were analyzed via XRD using a Rigaku D/max 2400 diffractometer with monochromated $\mathrm{Cu}_{\mathrm{Ka}}$ radiation $(\lambda \mathrm{k} \alpha=0.154056 \mathrm{~nm})$.
The microstructures of the alloys and reaction byproducts were characterized via SEM using an FEI inspect F50 scanning electron microscope with a Quanta 600EDX (EDS) system. To minimize the oxidation of the fractured surfaces of the samples, they were placed in a sample chamber as soon as they were cut.

The equipment used in hydrogen generation experiments was the same as that used in the study by He Tiantian et al. ${ }^{37)}$ Experiments were conducted for three different reaction temperatures (i.e., temperature of the water), viz. $30^{\circ} \mathrm{C}, 50^{\circ} \mathrm{C}$, and $70^{\circ} \mathrm{C}$. For each temperature, $0.3 \mathrm{~g}$ of the alloy was added to the reactor, and the test was repeated thrice; the averaged hydrogen generation rates were calculated for the different alloys. Based on these calculations, the yield curves for the cases with a hydrogen yield of less than $80 \%$ were selected to obtain the hydrogen generation rates of the samples by calculating the slopes of the selected curves using linear curve fitting. The results reported in this paper are the averages for the three repeated measurements. The temperature of the room in which the experiments were conducted was set to a constant $20^{\circ} \mathrm{C}$ with a humidity of less than $20 \%$.

\section{Results}

\subsection{X-ray diffraction analysis}

Figure 1 shows the XRD spectra of the Al-Ga-In-Sn alloys with different $\mathrm{Al}-3 \mathrm{Ti}-0.3 \mathrm{C}$ content represented with

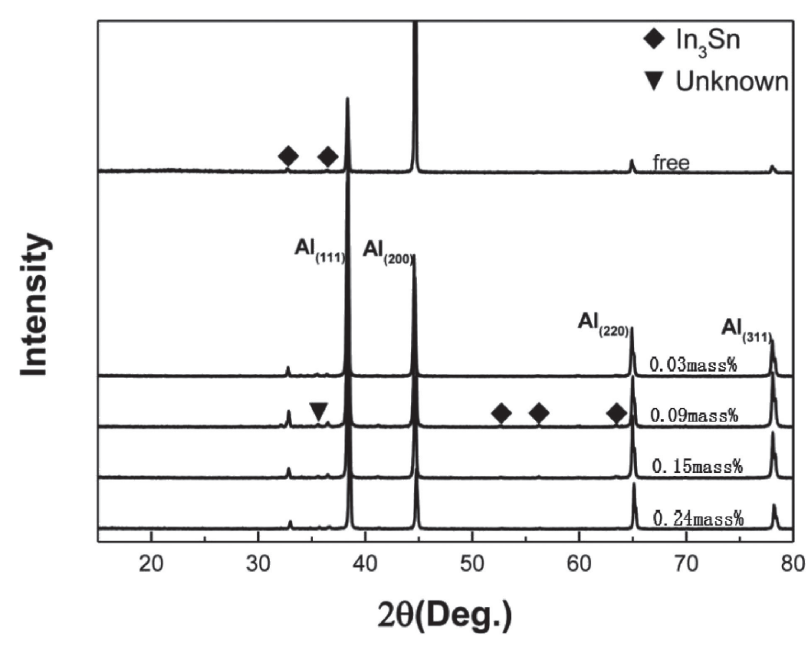

Fig. 1 XRD patterns of Al-Ga-In-Sn alloys with different Ti content.

Table 1 Chemical composition of alloys.

\begin{tabular}{cccccc}
\hline \multicolumn{7}{c}{ Chemical composition of alloys(mass\%) } \\
\hline Alloy code & Ti & Ga & In & Sn & Al \\
$1 \#$ & 0 & 3.8 & 1.5 & 0.7 & Bal. \\
$2 \#$ & 0.03 & 3.8 & 1.5 & 0.7 & Bal. \\
$3 \#$ & 0.06 & 3.8 & 1.5 & 0.7 & Bal. \\
$4 \#$ & 0.09 & 3.8 & 1.5 & 0.7 & Bal. \\
$5 \#$ & 0.12 & 3.8 & 1.5 & 0.7 & Bal. \\
$6 \#$ & 0.15 & 3.8 & 1.5 & 0.7 & Bal. \\
$7 \#$ & 0.18 & 3.8 & 1.5 & 0.7 & Bal. \\
$8 \#$ & 0.24 & 3.8 & 1.5 & 0.7 & Bal. \\
\hline
\end{tabular}


their equivalent Ti content. Based on the XRD spectra, it is clear that all alloys contain an $\mathrm{Al}(\mathrm{Ga})$ solid solution and intermetallic compound $\mathrm{In}_{3} \mathrm{Sn}$, which is consistent with the experimental results reported by He Tiantian et al. ${ }^{37)}$ When $\mathrm{Al}$ (111) and $\mathrm{Al}$ (200) are not refined in the alloy, the ratio of the diffraction peak intensities of the $\mathrm{Al}$ (111) to $\mathrm{Al}$ (200) crystal planes is about 0.27 , which is considerably smaller than that between $\mathrm{Al}(111)$ and $\mathrm{Al}(200)$ in pure $\mathrm{Al}$, which is 2.128 (PDF Card 040787). This difference in intensity ratios indicates that the growth of $\mathrm{Al}$ grains in the alloy without the Al-3Ti-0.3C refiner is directional during solidification, which, in turn, signifies that $\mathrm{Al}$ grains easily grow along the grain plane (200). However, when the Ti content in the alloy is more than 0.03 mass $\%$, the ratio of the diffraction peak intensities of $\mathrm{Al}$ (111) to $\mathrm{Al}$ (200) is about 1.27, which indicates that the grain in the $\mathrm{Al}$ alloy with the refiner tends to grow uniformly in all directions.

\subsection{SEM observation and EDX analysis}

Figures 2 and 3 show the fracture morphology of the $\mathrm{Al}-$ $\mathrm{Ga}-\mathrm{In}-\mathrm{Sn}$ alloys with different $\mathrm{Al}-3 \mathrm{Ti}-0.3 \mathrm{C}$ content and variations in their grain and second phase particle sizes, respectively. Without the refiner, the obtained $\mathrm{Al}$ grains are coarse and columnar (Fig. 2(a)) with a width of about $632 \mu \mathrm{m}$. However, when the refiner is added to the alloy, the grain of $\mathrm{Al}$ changed from columnar to equiaxed. Further- more, with an increase in the Ti content, the Al grain size gradually decreased. It can be seen from Fig. 3(a) that when the Ti content increases from 0.03 mass $\%$ to 0.24 mass $\%$, the Al grain size reduces from about $181 \mu \mathrm{m}$ to about $73 \mu \mathrm{m}$. In contrast, the grain size of the Al with 1 mass $\%$ pure $\mathrm{Ti}$ is about $60 \mu \mathrm{m} .{ }^{37)}$ Therefore, compared with pure Ti, Al-3Ti$0.3 \mathrm{C}$ refined the grain in the alloy more significantly. In addition, from Fig. 3(b), it can be seen that a large number of bright white grain boundary phases are distributed at the grain boundaries of $\mathrm{Al}$.

The composition of the Al grain and grain boundary phase was analyzed via EDX; these results are listed in Table 2. From the EDX results, it is clear that there is a small amount of $\mathrm{Ga}$ in the alloy grains, which is a result of the partial Ga solid solution in the Al lattice. The bright white precipitates contain large amounts of In and Sn, whereas small amounts of $\mathrm{Al}$ and $\mathrm{Ga}$. In particular, the atomic ratio of $\mathrm{In}: \mathrm{Sn}$ is approximately $3: 1$, indicating that the bright white precipitates are primarily composed of $\operatorname{In}_{3} \mathrm{Sn}$, which is consistent with the results obtained from the XRD analysis.

Figure 4 shows the local enlargement in the fracture morphology of the alloys with different Ti content. As can be seen from Fig. 4, when the $\mathrm{Ti}$ content is less than 0.12 mass $\%$, only bright, white GIS phases can be observed at the $\mathrm{Al}$ grain boundaries; however, when the Ti content is higher than 0.12 mass $\%$, in addition to bright, white GIS
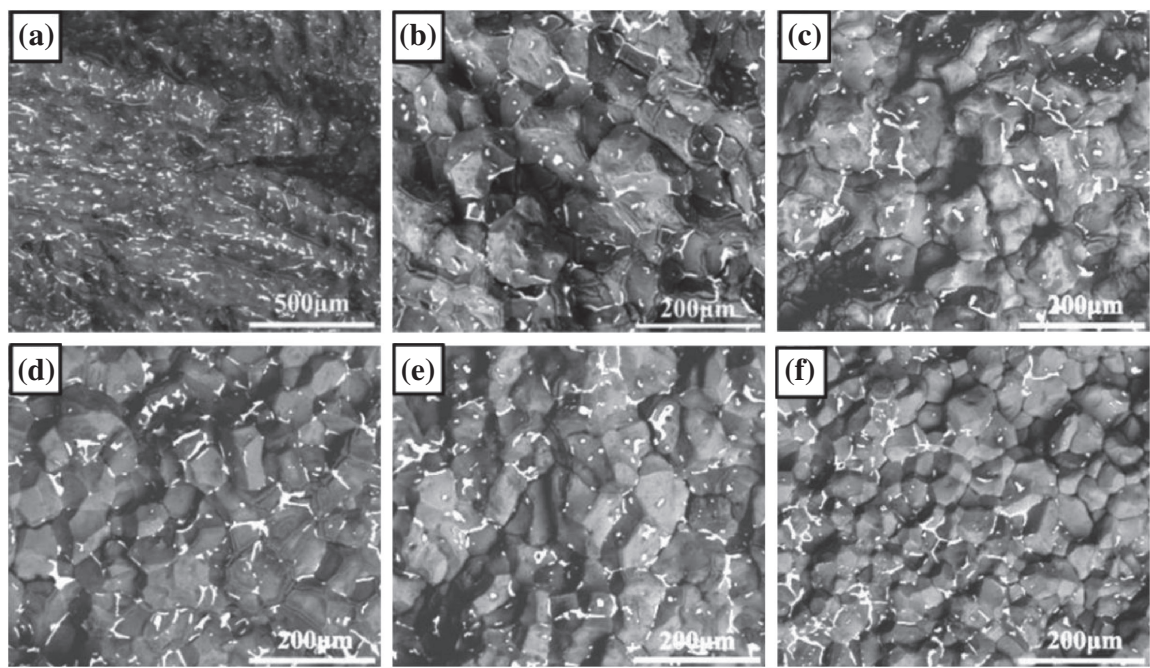

Fig. 2 The fracture surfaces of Al-Ga-In-Sn alloys with different Ti content (a) 0.00 mass $\%$ Ti (b) 0.03 mass $\%$ Ti (c) 0.09 mass $\%$ Ti (d) 0.15 mass $\% \mathrm{Ti}$ (e) 0.18 mass $\% \mathrm{Ti}$ and (f) 0.24 mass $\% \mathrm{Ti}$
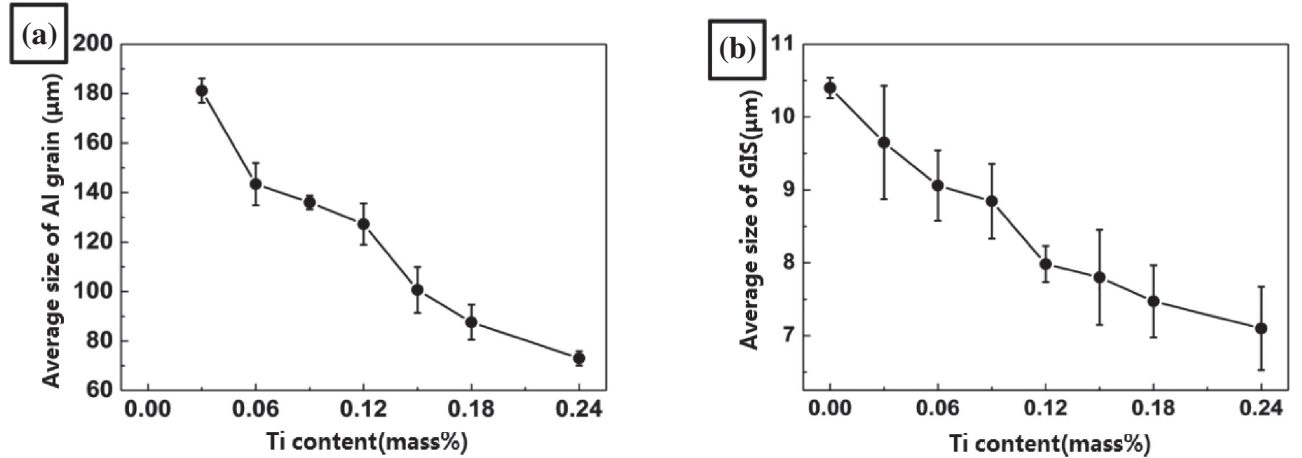

Fig. 3 (a) Plot of Al grain sizes with different Ti content in the alloys. (b) Plot of GIS phase sizes with different Ti content in the alloys. 
Table 2 Compositions of Al-Ga-In-Sn alloys with different Ti content obtained using EDX.

Composition of 6 mass $\%$ Al-Ga-Sn alloys with different Ti contents obtained via EDX

\begin{tabular}{|c|c|c|c|c|c|c|c|}
\hline \multirow{2}{*}{$\begin{array}{l}\text { Ti Content } \\
\text { in Sample }\end{array}$} & \multirow{2}{*}{ Spectrum } & \multirow{2}{*}{ Phase } & \multicolumn{5}{|c|}{ Element(mass $\%)$} \\
\hline & & & $\mathrm{Al}$ & $\mathrm{Ga}$ & In & $\mathrm{Sn}$ & $\mathrm{Ti}$ \\
\hline \multirow[t]{2}{*}{0.00 mass $\%$} & 1 & $\mathrm{G}$ & 93.07 & 6.14 & 0.79 & & \\
\hline & 2 & GB & 44.59 & 4.96 & 36.24 & 14.22 & \\
\hline \multirow[t]{3}{*}{0.06 mass $\%$} & 3 & $\mathrm{G}$ & 97.66 & 1.86 & 0.24 & 0.23 & \\
\hline & 4 & GB & 14.10 & 4.03 & 57.92 & 23.95 & \\
\hline & 5 & GB & 95.53 & 1.81 & 1.97 & 0.69 & \\
\hline \multirow[t]{2}{*}{0.09 mass $\%$} & 6 & $\mathrm{G}$ & 96.60 & 3.40 & & & \\
\hline & 7 & GB & 25.41 & 4.80 & 51.44 & 18.36 & \\
\hline \multirow[t]{3}{*}{0.15 mass $\%$} & 8 & $\mathrm{G}$ & 97.93 & 2.07 & & & \\
\hline & 9 & GB & 34.06 & 5.22 & 43.71 & 17.02 & \\
\hline & 10 & GB & 65.61 & 2.63 & 0.81 & 0.50 & 30.46 \\
\hline \multirow[t]{3}{*}{0.18 mass $\%$} & 11 & $\mathrm{G}$ & 96.82 & 2.45 & 0.36 & 0.37 & \\
\hline & 12 & GB & 11.21 & 4.91 & 59.04 & 24.83 & \\
\hline & 13 & GB & 56.94 & 6.11 & 2.71 & 0.74 & 33.50 \\
\hline
\end{tabular}
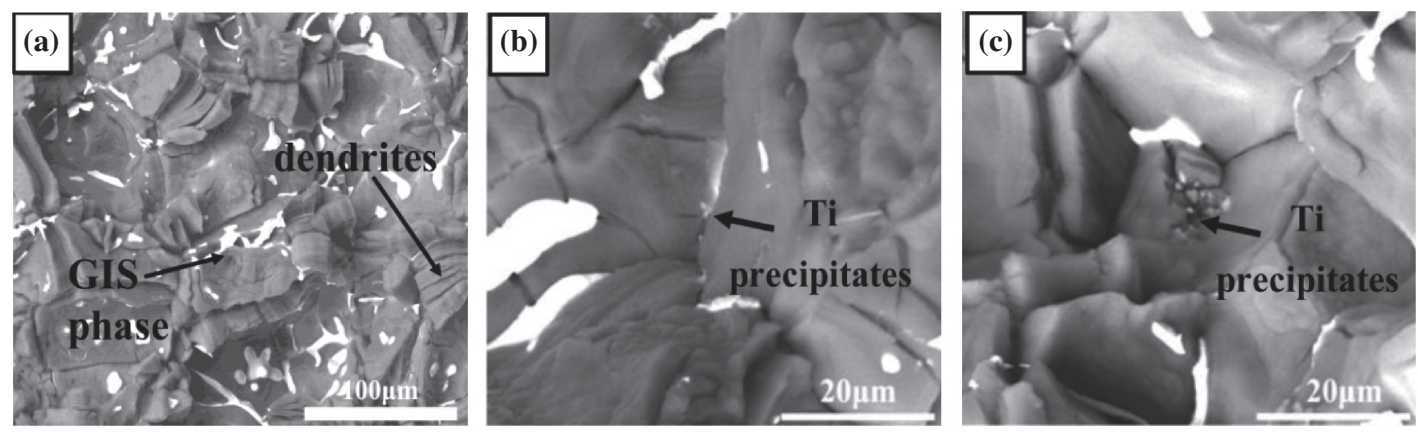

Fig. 4 Fracture surfaces of Al-Ga-In-Sn alloys with different Ti content: (a) 0.06 mass $\%$ Ti (b) 0.12 mass $\%$ Ti (c) 0.18 mass $\%$ Ti.

phases, light gray precipitates containing $\mathrm{Ti}$ can also be observed at the grain boundaries (Fig. 4(b) and 4(c)). This is because with an increase in the Ti content in the alloy, the amount of precipitate containing $\mathrm{Ti}$ also increases. In particular, the EDS results indicate that the Ti content in precipitates increases with an increase in the Ti content in the alloy itself.

From Fig. 4(a), many lamellar (dendritic) structures can be observed in the $\mathrm{Al}$ grains. The lamellar structure is only a few micrometers thick. The EDS results confirm that the lamellar structure is $\mathrm{Al}(\mathrm{Ga})$ solid solution, which indicates that there are many $\mathrm{Al}$ dendrites in the grain of the $\mathrm{Al}$ alloy.

\subsection{Measurements of Al-water reactivity of alloys}

Through our experiments, it was observed that the refined Al-Ga-In-Sn alloy reacted vigorously with water immediately after coming in contact with it, rapidly fragmenting into particles. The higher the temperature of the water, the greater the degree of fractures was. Figure 5 shows the hydrogen production curves for the alloys with different Ti content and different water temperatures. The hydrogen production rate of an alloy can be obtained by linear fitting of the segments whose hydrogen production rate is less than $80 \%$ on the hydrogen production curve. Figure 6 shows the statistical results for the hydrogen production rate and hydrogen generation yields for alloys with different Ti content.

In particular, from Fig. 6(a), it is clear that the hydrogen production rate of an alloy is related to the Ti content in it and the temperature of water. For the same water temperature, when the $\mathrm{Ti}$ content in the alloy is less than 0.12 mass $\%$, the hydrogen production rate of the alloy increases with an increase in the Ti content; however, it remains almost unchanged with a further increase in the $\mathrm{Ti}$ content. When the Ti content reaches 0.12 mass $\%$, the hydrogen production rate of the alloy reaches the maximum value for a particular water temperature. For example, the hydrogen production rate of the alloy with 0.12 mass $\% \mathrm{Ti}$ is $540.62 \mathrm{ml} / \mathrm{g}$.Al.min, which is about 2 times of that of Ti-free alloy. Furthermore, for the same Ti content in the alloy, the hydrogen production rate increases with an increase in the water temperature.

The conversion rate of the Al-water reaction is also related to water temperature and Ti content in the alloy (Fig. 6(b)). The conversion rate of the alloy reaches its maximum when the Ti content is 0.09 mass $\%$. In particular, the hydrogen conversion rate is $75 \%$ for the alloy without the refiner at 

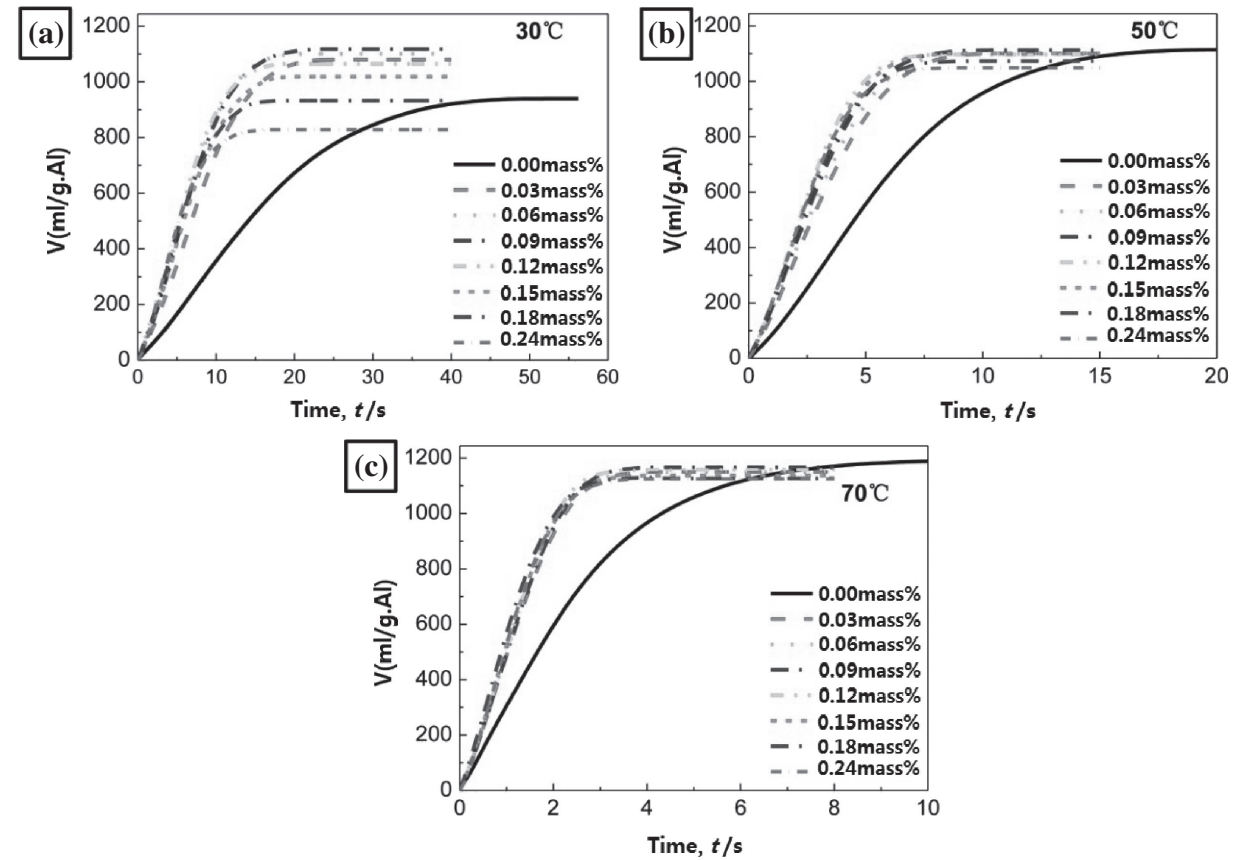

Fig. 5 Hydrogen generation curves of $\mathrm{Al}-\mathrm{Ga}-\mathrm{In}-\mathrm{Sn}$ alloys with different $\mathrm{Ti}$ content for the following water temperatures: (a) $30^{\circ} \mathrm{C}$ (b) $50^{\circ} \mathrm{C}$ and (c) $70^{\circ} \mathrm{C}$.
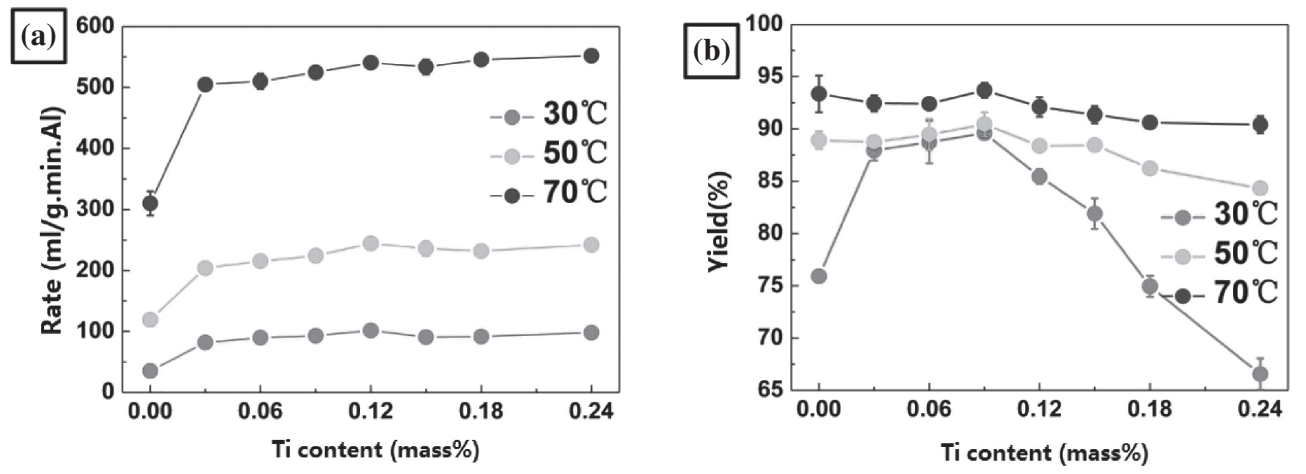

Fig. 6 (a) Hydrogen generation rates and (b) yields of Al-Ga-In-Sn alloys as a function of the Ti content in them.

$30^{\circ} \mathrm{C}$, which is lower than that of the alloy prepared via arc melting by He Tiantian et al., in which case, it was $90 \% .{ }^{37)}$ Furthermore, the hydrogen conversion rate of alloys with $\mathrm{Ti}$ content of $0.03-0.15$ mass $\%$ formed via atmospheric pressure casting is over $80 \%$. However, when the Ti content increases from $0.15-0.24$ mass $\%$, the hydrogen yield of the cast alloy decreases from about $82 \%$ to $66 \%$. The hydrogen conversion rate of the alloy also increases with an increase in the water temperature. The hydrogen conversion rate of all atmospheric casting alloys is more than $80 \%$ at a water temperature of $50^{\circ} \mathrm{C}$. At this temperature, when the $\mathrm{Ti}$ content in the alloy is increased from $0.03-0.24$ mass $\%$, the hydrogen yield of the alloy decreases from $88.74 \%$ to $84.32 \%$. Moreover, when the water temperature is increased to $70^{\circ} \mathrm{C}$, the hydrogen conversion rate for the Ti-free alloy is $93 \%$. Except for the alloy with a Ti content of 0.09 mass $\%$, the hydrogen conversion rates of the alloys with $\mathrm{Ti}$ content are slightly lower than that of the alloy without $\mathrm{Ti}$; however, all of them are above $90 \%$. In addition, considering the experimental results reported by $\mathrm{He}$ Tiantian et al., ${ }^{37)}$ for the same $\mathrm{Ti}$ content, atmospheric pressure casting alloys have higher hydrogen production and conversion rates than alloys produced via arc melting.

\subsection{Reaction byproducts}

The reaction between $\mathrm{Al}$ and water remains incomplete when the temperature of the water is $30^{\circ} \mathrm{C}$. XRD measurements were used to analyze the phase of the products deposited at the bottom of the reactor after the completion of the reaction of alloys containing 0.06 mass $\%$ and 0.24 mass $\%$ Ti with water; these results are shown in Fig. 7. It can be seen from the figure that the byproducts of the alloys with $\mathrm{Ti}$ content of $0.06 \mathrm{mass} \%$ and $0.24 \mathrm{mass} \%$ contain $\alpha$-Al, $\mathrm{Al}(\mathrm{OH})_{3}$, and $\mathrm{In}_{3} \mathrm{Sn}$ phases, and the $\mathrm{In}_{3} \mathrm{Sn}$ phases for these two alloys are almost the same. The peak strength of the $\mathrm{Al}(\mathrm{OH})_{3}$ phase for the alloy with a Ti content of 0.24 mass $\%$ is lower than that of the alloy with a $\mathrm{Ti}$ content of 0.06 mass \%; however, the peak strength of the $\alpha$-Al phase in the alloy with a Ti content of 0.24 mass $\%$ is higher than that of the other alloy, which indicates that more $\mathrm{Al}$ participates in the Al-water reaction in the case of the alloy with a Ti content of 0.06 mass $\%$ to form the $\mathrm{Al}(\mathrm{OH})_{3}$ phase. 


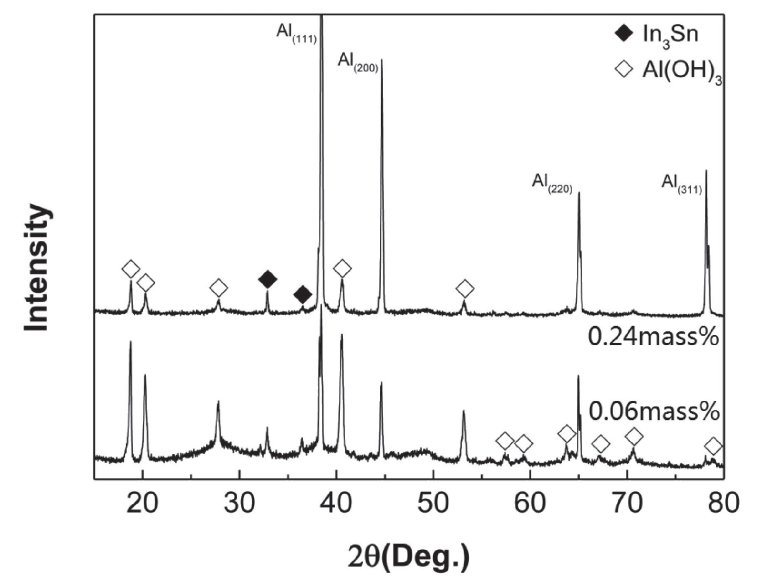

Fig. 7 XRD patterns of the reaction byproducts for Al-Ga-In-Sn alloys with different Ti content.

\section{Discussion}

When 0.03 mass\% Ti (Al-3Ti-0.3C) is added in Al-GaIn-Sn alloy, it is found $\mathrm{Al}$ grain is changed into equiaxed one and the size of $\mathrm{Al}$ grain is reduced compared to that of $\mathrm{Al}-$ Ga-In-Sn alloy with 0.00 mass\% Ti. In particular, when the Ti content reaches 0.15 mass $\%$, the grain size of the Al alloy is refined to $100 \mu \mathrm{m}$. In contrast, when 0.7 mass $\%$ pure Ti is added to the Al-Ga-In-Sn alloy, the grain is equiaxed with a size of $108 \mu \mathrm{m}$. These observations indicate that a small amount of $\mathrm{Al}-3 \mathrm{Ti}-0.3 \mathrm{C}$ can refine the $\mathrm{Al}-\mathrm{Ga}-\mathrm{In}-\mathrm{Sn}$ alloy more effectively compared with pure Ti. As previously mentioned, this is because the TiC phase in the Al-3Ti-0.3C refiner is beneficial to the formation of a large number of $\mathrm{TiAl}_{3}$ particles in the $\mathrm{Al}$ melt, which increase the heterogeneous nucleation rate of $\alpha-\mathrm{Al}$ and refines the $\mathrm{Al}$ grain size. Furthermore, because $\mathrm{Al}$ grains grow uniformly in all directions, equiaxed grains are formed. On increasing the $\mathrm{Al}-3 \mathrm{Ti}-0.3 \mathrm{C}$ content in the alloy, the number of $\mathrm{TiAl}_{3}$ particles increase, consequently increasing the nucleation rate of $\alpha$-Al, leading to smaller grain sizes.

The Ti in Al-3Ti-0.3C not only promotes the nucleation of $\alpha$-Al, but also allows for the accumulation of excess Ti atoms at the liquid-solid interface. Because $\mathrm{In}$ and $\mathrm{Sn}$ are not soluble in $\mathrm{Al}$, and $\mathrm{Ga}$ is only slightly soluble in $\mathrm{Al}$, a large number of $\mathrm{Ti}, \mathrm{Ga}, \mathrm{In}$, and $\mathrm{Sn}$ atoms will accumulate at the liquid-solid interface after solute redistribution. Because these atoms form component undercooling regions in the unsolidified $\mathrm{Al}$ melt, $\alpha$-Al will grow in the component undercooling region in the form of $\mathrm{Al}$ dendrites. ${ }^{41-43)}$ As the $\mathrm{Al}$ grains grow, a large number of In and $\mathrm{Sn}$ atoms and some $\mathrm{Ga}$ atoms at the liquid-solid interface are pushed to the surface of $\mathrm{Al}$ grains to form GIS phases at the grain boundary. Furthermore, a small number of In, Sn, and Ga atoms will form GIS phases between Al dendrites because they could not transfer to the grtain interface in time, so they stay in the dendrites interfaces.

Compared with the Ti-free alloys, the Al-water reaction with the Ti-containing alloys will inevitably change after grain refinement. At the same water temperature (Fig. 6(a)), with an increase in the $\mathrm{Ti}$ content $(<0.12$ mass $\%)$, the hydrogen production rate of the alloy gradually increases because of the decrease in Al grain size. In particular, the hydrogen production rate of the alloy with a Ti content of 0.12 mass $\%$ is about twice that of the Ti-free alloy. Furthermore, the width of Ti-free columnar Al crystal is $632 \mu \mathrm{m}$, which is about 5 times the grain size of the Al alloy containing 0.12 mass $\%$ Ti (specifically $127 \mu \mathrm{m}$ ). Because of transgranular fractures in Ti-containing alloys, it is impossible to accurately calculate the size of the GIS phase at the interface. However, the trend that the GIS phase area increases with a decrease in alloy grain size means that the GIS phase area increases with an increase in the Ti content of the alloy. The researchs ${ }^{33,34)}$ show that the hydrogen production rate of the alloy is inversely proportional to the $\mathrm{Al}$ grain size and directly proportional to the area of the GIS phase on the surface of Al grain, it can be inferred that the ratio of the hydrogen production rate of the alloy containing 0.12 mass \% Ti to the that of the alloy without Ti should be greater than 5. However, based on our results, it is clear that the ratio of hydrogen production rate between the two alloys is less than 5, which indicates that the Ti in the alloys reduces the hydrogen production rate to a certain degree.

On further increasing the Ti content $(>0.12$ mass $\%)$, the Al grain size continues to decrease; however, the hydrogen production rate of the Ti-containing alloys remains unchanged. This further indicates that the hydrogen production rate of Ti-containing alloys is not only related to the Al grain size and GIS phase area at the grain boundaries, but also to the Ti content in alloys. The results of $\mathrm{Al}$-water reaction using the alloy prepared with pure $\mathrm{Ti}$ as the refiner also show that $\mathrm{Ti}$ in the alloy hinders the Al-water reaction. These experimental results can be explained as follows. Because Ti does not react with water, the soluble $\mathrm{Ti}$ in the grain of the $\mathrm{Al}$ alloy will occupy some active positions of Al, which will inevitably lead to a smaller effective area of contact between $\mathrm{Al}$ and water. During the reaction of the alloy with water, as the $\mathrm{Al}$ is consumed, Ti continuously deposits on the surface of the unreacted Al grains, which hinders the diffusion of $\mathrm{Al}$ atoms into the GIS phase. Therefore, $\mathrm{Ti}$ results in the decrease of the hydrogen production rate and hydrogen yield of the alloy. Furthermore, the analysis of the reaction byproducts indicates that the $\mathrm{Al}$ content in the byproducts of the water reaction is higher with an alloy containing high $\mathrm{Ti}$ content and vice versa, which confirms our understanding that $\mathrm{Ti}$ in the alloy hinders the Al-water reaction. With an increase in the Ti content, the hindering effect of Ti on the Al-water reaction also increases. However, when the Ti content exceeds 0.12 mass $\%$, the hindering effect of $\mathrm{Ti}$ on the Al-water reaction is offset by the promotion of grain refinement because of it; therefore, the hydrogen production rate of an alloy with a Ti content greater than 0.12 mass $\%$ remains unchanged.

$\mathrm{Al}$ grain size is an important factor affecting the Al-water reaction of alloys. The hydrogen production rate and conversion rate of the different alloys differ because of the different grain sizes of alloys prepared via different methods. In particular, when the alloy is prepared via arc melting, the cooling rate during alloy solidification is relatively high; therefore, the grain size of the resulting alloy is small (the width of columnar crystal is $256 \mu \mathrm{m}$ ). However, an alloy prepared via atmospheric pressure casting has a relatively 
larger grain size (columnar grain width is $632 \mu \mathrm{m}$ ) because of the lower cooling rate during alloy solidification. Therefore, the hydrogen production rate of alloys prepared via atmospheric pressure casting is lower than of those prepared via arc melting.

When $\mathrm{Al}-3 \mathrm{Ti}-0.3 \mathrm{C}$ with a Ti content of 0.03 mass $\%$ is added to the alloy, the grain of the alloy is equiaxed, which is naturally smaller than that of the alloy without a refiner. Furthermore, the hydrogen production rate of the alloy containing 0.03 mass $\% \mathrm{Ti}$ at $30^{\circ} \mathrm{C}$ is higher than that of the alloy without a refiner, because a small amount of $\mathrm{Ti}$ in the grain of alloy offers little hindrance to the reaction between $\mathrm{Al}$ and water. Nevertheless, at the same temperature $\left(30^{\circ} \mathrm{C}\right)$, an increase in the $\mathrm{Ti}$ content of the alloy leads to $\mathrm{Ti}$ precipitates in the $\mathrm{Al}$ grains and grain boundaries, which hinders the reaction between $\mathrm{Al}$ and water, gradually decreasing the hydrogen production rate of the alloy.

In addition to the grain size, the temperature of the water used for the reaction is also an important factor affecting hydrogen production rate and hydrogen yield. In general, with an increase in the water temperature $\left(>50^{\circ} \mathrm{C}\right)$, the $\mathrm{Al}-$ water reaction rate increases. A large number of hydrogen bubbles produced by the Al-water reaction can displace Ti deposited on the surface of the $\mathrm{Al}$ grains, which reduces the hindrance Ti offers to the Al-water reaction. Therefore, the hydrogen production rate and hydrogen yield of the alloys increase with an increase in the water temperature. When the water temperature is $70^{\circ} \mathrm{C}$ (Fig. 6(b)), the hydrogen yield for the different alloys reaches more than 90\%, which indicates that the hindering effect of $\mathrm{Ti}$ on the hydrogen production rate and yield of alloys becomes weak above this temperature.

\section{Conclusions}

The effect of different amounts of $\mathrm{Al}-3 \mathrm{Ti}-0.3 \mathrm{C}$ as a refiner in Al-Ga-In-Sn casting alloy on the alloy's microstructure and Al-water reaction were studied. The following conclusions were drawn:

Compared with pure $\mathrm{Ti}, \mathrm{Al}-3 \mathrm{Ti}-0.3 \mathrm{C}$ had a more remarkable grain refinement effect.

The grain of the alloys containing Al-3Ti-0.3C was equiaxed with lamellar dendrites in the grain. When the equivalent $\mathrm{Ti}$ content in the alloy was higher than 0.12 mass $\%$, precipitates containing $\mathrm{Ti}$ appear at the grain boundary. The amount of precipitates increases with increase in the Ti content.

When the temperature of the water used for the Al-water reaction is low $\left(<50^{\circ} \mathrm{C}\right)$, the hydrogen production rate using the Al-Ga-In-Sn alloy decreases with an increase in the Ti content. However, with an increase in the water temperature, the hindering effect of $\mathrm{Ti}$ on the reaction between the alloy and water is weakened, leading to a hydrogen production rate of more than $90 \%$.

The hydrogen production rate of the alloy with a Ti content of 0.12 mass $\%$ is the highest. Increasing the $\mathrm{Ti}$ content beyond this amount leads to an increase in the hindering effect of $\mathrm{Ti}$ on the reaction; however, the hydrogen production rate of the alloy remains almost unchanged. Thus, based on our results, the optimum amount of Al-3Ti-
$0.3 \mathrm{C}$ to add to the $\mathrm{Al}-\mathrm{Ga}-\mathrm{In}-\mathrm{Sn}$ alloy for enhanced hydrogen production rate and yield is 2.4 mass $\%$.

\section{Acknowledgments}

This research was financially supported by the National Natural Science Foundations of China (Grant 11462021).

\section{REFERENCES}

1) W. Wang, D.M. Chen and K. Yang: Int. J. Hydrogen Energ. 35 (2010) 12011-12019.

2) J.T. Ziebarth, J.M. Woodall, R.A. Kramer and G. Choi: Int. J. Hydrogen Energ. 36 (2011) 5271-5279.

3) Z.Y. Deng, Y.B. Tang, L.L. Zhu, Y. Sakka and J.H. Ye: Int. J. Hydrogen Energ. 35 (2010) 9561-9568.

4) A.V. Parmuzina and O.V. Kravchenko: Int. J. Hydrogen Energ. 33 (2008) 3073-3076.

5) H.Z. Wang, D.Y.C. Leung, M.K.H. Leung and M. Ni: Renew. Sustain. Energy Rev. 13 (2009) 845-853.

6) L. Soler, J. Macanás and M. Muñoz: J. Power Sources 169 (2007) 144149.

7) V. Rosenband and A. Gany: Int. J. Hydrogen Energ. 35 (2010) 1089810904.

8) L. Soler, A.M. Candela, J. Macanas, M. Munoz and J. Casado: Int. J. Hydrogen Energ. 35 (2010) 1038-1048.

9) V. Shmelev, H. Yang and C. Yim: Int. J. Hydrogen Energ. 41 (2016) 14562-14572.

10) L.Q. Zhang, Y.S. Tang, Y.L. Duan, L.Q. Hou, L.S. Cui, F. Yang, Y.J. Zheng, Y.F. Li and J.Y. Huang: Chem. Eng. J. 320 (2017) 160-167.

11) H.B. Dai, G.L. Ma, H.J. Xia and P. Wang: Energy Environ. Sci. 4 (2011) 2206-2212

12) G.L. Ma, H.B. Dai, D.W. Zhuang, H.J. Xia and P. Wang: Int. J. Hydrogen Energ. 37 (2012) 5811-5816.

13) S. Elitzur, V. Rosenband and A. Gany: Int. J. Hydrogen Energ. 42 (2017) 14003-14009.

14) V. Shmelev, V. Nikolaev, J.H. Lee and C. Yim: Int. J. Hydrogen Energ. 41 (2016) 16664-16673.

15) C.C. Wang, Y.C. Chou and C.Y. Yen: Procedia Eng. 36 (2012) 105113.

16) M.Q. Fan, L.X. Sun and F. Xu: Renew. Energy 36 (2011) 519-524.

17) F. Li, B.Z. Zhu, Y.L. Sun and W. Tao: Int. J. Hydrogen Energ. 42 (2017) 3804-3812.

18) H.Q. Wang, Z. Wang, Z.H. Shi, X.Z. Gong, J.W. Cao and M.Y. Wang: Energy 131 (2017) 98-105.

19) W.J. Yang, W. Shi, C. Chen, T.Y. Zhang, J.Z. Liu, Z.H. Wang and J.H. Zhou: Int. J. Hydrogen Energ. 42 (2017) 3598-3604.

20) P. Li, J. Wang, X.X. Zhang, X.M. Hou, B.J. Yan, H.W. Guo and S. Seetharaman: Int. J. Hydrogen Energ. 42 (2017) 12956-12966.

21) G.N. Ambaryan, M.S. Vlaskin, A.O. Dudoladov, E.A. Meshkov, A.Z. Zhuk and E.I. Shkolnikov: Int. J. Hydrogen Energ. 41 (2016) 1721617224.

22) Y. Liu, X.H. Wang, H.Z. Liu, Z.H. Dong, S.Q. Li, H.W. Ge and M. Yan: Energy 84 (2015) 714-721.

23) B. Alinejad and K. Mahmoodi: Int. J. Hydrogen Energ. 34 (2009) 7934-7938

24) S.C. Tan, H. Gui, X.H. Yang, B. Yuan, S.H. Zhan and J. Liu: Int. J. Hydrogen Energ. 41 (2016) 22663-22667.

25) J.L. López-Miranda and G. Rosas: Int. J. Hydrogen Energ. 41 (2016) 4054-4059.

26) W.Z. Gai, W.H. Liu, Z.Y. Deng and J.G. Zhou: Int. J. Hydrogen Energ. 37 (2012) 13132-13140.

27) H. Wang, Y. Chang, S. Dong, Z. Lei, Q. Zhu, P. Luo and Z. Xie: Int. J. Hydrogen Energ. 38 (2013) 1236-1243.

28) H.Z. Wang, D.Y.C. Leung, M.K.H. Leung and M. Ni: Renew. Sustain. Energy Rev. 13 (2009) 845-853.

29) V. Rosenband and A. Gany: Int. J. Hydrogen Energ. 35 (2010) 1089810904.

30) S.C. Tan, H. Gui, X.H. Yang, B. Yuan, S.H. Zhan and J. Liu: Int. J. Hydrogen Energ. 41 (2016) 22663-22667. 
31) Y. Liu, X. Liu, X. Chen, S. Yang and C. Wang: Int. J. Hydrogen Energ. 42 (2017) 10943-10951.

32) K. Mahmoodi and B. Alinejad: Int. J. Hydrogen Energ. 35 (2010) 5227-5232.

33) W. Wang, X.M. Zhao, D.M. Chen and K. Yang: Int. J. Hydrogen Energ. 37 (2012) 2187-2194.

34) W. Wang, W. Chen, X.M. Zhao, D.M. Chen and K. Yang: Int. J. Hydrogen Energ. 37 (2012) 18672-18678.

35) T.T. He, W. Wang, W. Chen, D.M. Chen and K. Yang: J. Mater. Sci Technol. 33 (2017) 397-403.

36) T.T. He, W. Wang, W. Chen, D.M. Chen and K. Yang: Int. J. Hydrogen Energ. 42 (2017) 5627-5637.

37) T.T. He, W. Wang, D.M. Chen and K. Yang: Int. J. Hydrogen Energ. 39
(2014) 684-691.

38) G.K. Sigworth: Scr. Mater. 34 (1996) 919-922.

39) P. Schumacher, A.L. Greer, J. Worth, P.V. Evans, M.A. Kearns, P. Fisher and A.H. Green: Mater. Sci. Technol. 14 (1998) 394-404.

40) N. Li, L. Ma, L. Xiang, S. Qiu and P. Zhao: Mater. Trans. 55 (2014) 387-390.

41) M. Easton and D. Stjohn: Metall. Mater. Trans. A 30 (1999) 16131623 .

42) M. Easton and D. Stjohn: Metall. Mater. Trans. A 30 (1999) 16251633.

43) T. Chandrashekar, M.K. Muralidhara, K.T. Kashyap and P. Raghothama Rao: Int. J. Adv. Manuf. Technol. 40 (2009) 234-241. 